\title{
Non-communicating supratentorial subarachnoid cysts
}

\author{
Y. S. BHANDARI ${ }^{1}$ \\ From the Salford Royal Hospital, Salford and Royal Manchester Children's Hospital, \\ Pendlebury, Manchester
}

SUMMARY The clinical and radiological features and operative treatment of six patients with supratentorial subarachnoid cysts are reviewed. Five were adults aged 37 to 57 years and the other a male infant, aged 8 months. Three patients presented with epilepsy and hemiparesis, one with epilepsy without signs, another as Parkinsonian syndrome, and the infant with hydrocephalus. Diagnosis was revealed at operation in four cases, in one case by ventriculography, and in one case the lesion was strongly suspected on angiographic appearances. Surgical treatment is highly effective, since the cystic lesion is benign in nature, but recurrence of symptoms is not unusual and repeated evacuation of the cyst may be required. It is, therefore, considered essential to conduct a prolonged and careful follow-up.

Cerebral arachnoid cysts presenting as intracranial space occupying lesions were described as a clinical entity by Starkman, Brown and Linell (1958). Although these cysts lie in the brain substance, they do not communicate with the ventricular system or subarachnoid space. They give rise to symptoms and signs of raised intracranial pressure and are associated with other manifestations similar to those commonly associated with the neoplasms. Features of six cases of benign supratentorial cysts are reported below.

\section{CASE 1}

(S.R.H.3065.) P.O'D., a male aged 37 years, had, for six months, experienced difficulty in writing and on two occasions had transient episodes of speech difficulty and confusion in which he felt vaguely drunk. There was no history of trauma, infection, or haemorrhage in the past.

After a generalized convulsive seizure, he was admitted to a hospital abroad. No abnormal clinical or radiological signs were found. Cerebrospinal fluid (CSF) was normal, containing $17 \mathrm{mg}$ protein $/ 100 \mathrm{ml}$. Pneumoencephalography showed a cut off in the tip of the left temporal horn and slight elevation of the left frontal horn. A lesion in the left Sylvian area was

1 Present address: Dept. of Neurosurgery, St. Barnabas Medical Centre, Livingston, N.J.07039 U.S.A. indicated. A left carotid angiogram confirmed the presence of an avascular space occupying lesion in the Sylvian area.

A left frontotemporal flap was turned, and on opening the dura mater a large cyst was seen. Medially the cyst extended to the insula and laterally was in contact with the temporal dura mater, inferiorly it overlapped the middle cerebral vessels and the roof was a clear thin-walled membrane. There was depression in the lateral and inferior quadrant of the frontal lobe. Sixty millilitres of clear colourless fluid was aspirated containing $48 \mathrm{mg}$ protein $/ 100 \mathrm{ml}$., then the cyst wall was removed. There was no communication between the ventricles and the cyst. The dura mater was closed and the bone flap replaced. On the eighth post-operative day, pink subdural fluid was aspirated. Further progress was satisfactory and there were no abnormal signs. The patient has remained well and has been leading a normal life for the last 14 years.

HISTOLOGY The cyst wall looked like normal arachnoid mater.

\section{CASE 2}

(S.R.H.1133.) N.W., a female aged 62 years, at the age of 46 years attended another hospital and a large arachnoid cyst was removed from the right Sylvian region. Eighty millilitres of clear colourless fluid was aspirated containing $80 \mathrm{mg}$ protein $/ 100 \mathrm{ml}$., before the removal of the cyst wall. She remained 
well until the age of 62 years, when she became depressed and developed mild headache. She was admitted to hospital because of symptoms developing after a fall down the stairs two weeks previously. Four days after the fall she became increasingly drowsy and 14 days later was admitted in an unconscious state, with a left spastic hemiplegia affecting the arm more than the leg. She developed status epilepticus and died of aspiration pneumonitis and pulmonary oedema.

POST-MORTEM EXAMINATION The dura mater was adherent in the region of the craniotomy flap, and on opening the dura mater a large cyst was seen occupying the right Sylvian fissure. The temporal pole was displaced posteriorly and the posterior inferior part of the frontal lobe was indented and pushed upwards (Figs 1 and 2). Medially the cyst extended to the sella turcica across the midline; laterally it was in contact with the temporal dura mater. The right optic nerve was stretched to nearly double its length. The optic chiasma was distorted to the left of the midline. The internal carotid artery and its branches were entangled in the meshes of arachnoid mater in the floor of the cyst. No opening was seen in the cyst. There was a large uncal herniation below the tentorium. The pituitary stalk was elongated and the gland was flattened.

The lungs showed oedema and pneumonic changes.

\section{CASE 3}

(R.M.C.H.50492.) D.O'M., a male aged 8 months, was born at full term after a normal delivery; he



FIG. 1. Case 2. Basal view showing the site of the 미 cyst. Note the depression in the orbital surface of the $\mathrm{C}$ frontal lobe and foreshortening of temporal lobe.

was referred because of gradual enlargement of the head for three months. There was no history of $\frac{\mathbb{O}}{3}$ trauma or illness. Neurological examination was normal but the head circumference was $6 \mathrm{~cm}$ abovec. the $97 \%$ average. Bilateral subdural tap was nega- $\vec{P} \overrightarrow{0}$

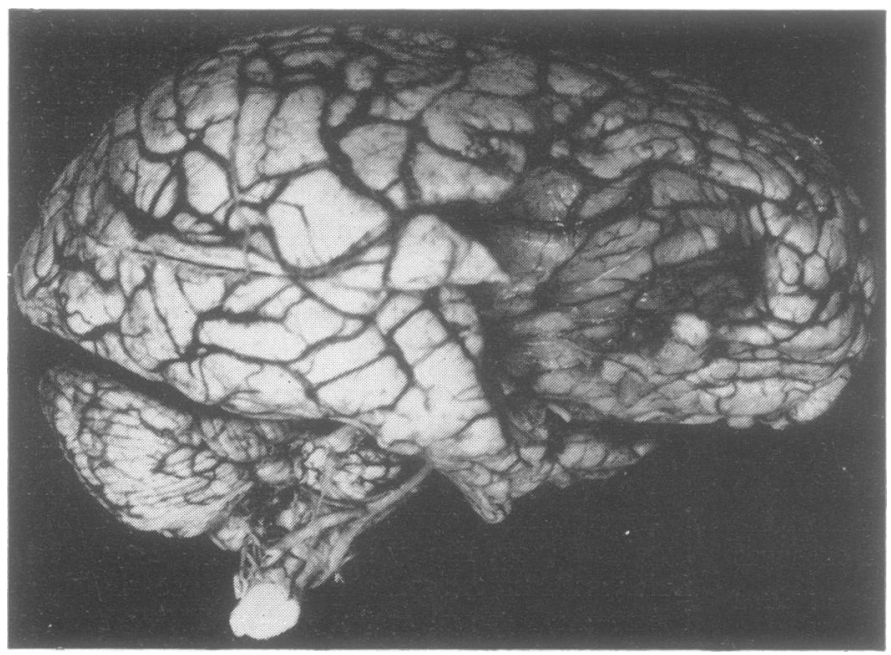

FIG. 2. Case 2. Right lateral view. Note the cyst cavity in the right Sylvian fissure. 
tive. Cerebrospinal fluid was normal with $10 \mathrm{mg}$ protein/100 ml. Ventriculography showed early hydrocephalic changes and the left temporal horn was slightly elevated.

At the age of 20 months, the child was admitted to hospital because of a history of severe screaming attacks for four months. During the attacks the child used to hold his head between the hands. Head circumference was $54 \mathrm{~cm}$. Bilateral 6th nerve palsies were observed.

Ventriculography through a right frontal burr hole revealed mild hydrocephalic changes with a minimal shift of the ventricles to the right. The left temporal horn was lifted upwards. A left carotid angiogram confirmed the presence of an avascular space occupying lesion in the Sylvian region (Figs 3 and 4).

A left frontotemporal flap was turned, and on opening the tense and bluish-looking dura mater a large cyst measuring $5 \mathrm{~cm}$ in diameter was seen. Medially, the cyst indented the inferior posterior part of the frontal lobe; laterally, it was in contact with the temporal dura mater. In the floor of the cyst, the carotid artery and its branches, and optic and oculomotor nerves were seen and the adjacent temporal lobe was foreshortened. The roof of the cyst was removed after aspirating $70 \mathrm{ml}$. of clear fluid. There was no communication between the cyst and the ventricle. The subarachnoid space along the tentorial edge was opened. The dura mater was closed.
The postoperative course was satisfactory and the child has remained well.

HISTOLOGY The cyst wall looked like normal arachnoid mater. Some areas were thicker than normal, due to proliferation of the cells in the deeper layers of arachnoid mater.

\section{CASE 4}

(S.R.H. 6538.) R.L., a female aged 57 years, presented with gradually increasing stiffness of the left arm and hand for $2 \frac{1}{2}$ years. During the six months before admission she had two attacks of twitching and shaking of the left arm, lasting for two to three minutes. There was no history of trauma or other illness.

The patient was well oriented in time and place. There was no papilloedema. There was gross spasticity in the left arm with finger clenching. The lower limbs were normal and the plantar reflexes were flexor.

Lumbar cerebrospinal fluid was normal, containing $48 \mathrm{mg}$ protein/100 ml. Ventricular cannulation through posterior parietal burr holes produced a slow flow of CSF from the left side, but a very profuse flow under pressure from the right. Air was introduced on the right side and a large cavity demonstrated in the right parietal convexity (Figs 5 and 6). Further air introduced into the left side demonstrated a small ventricular system shifted to the left (Fig. 7).

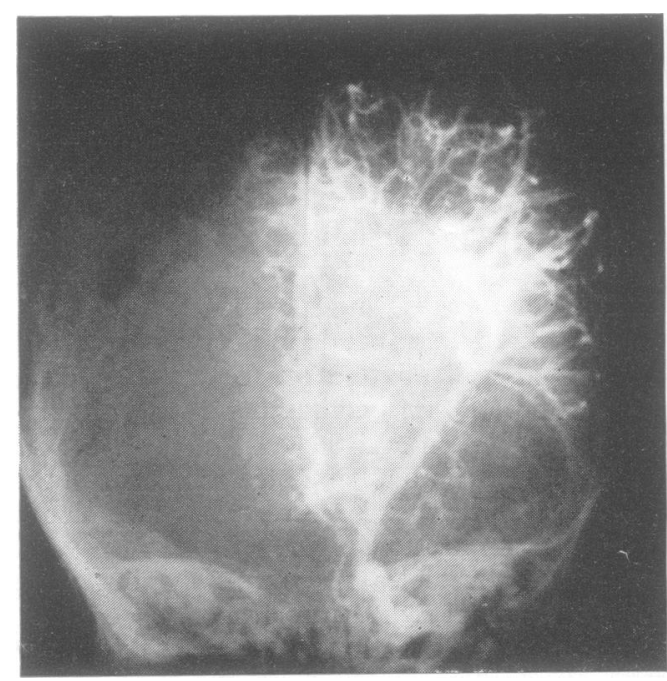

FIG. 3. Case 3. Left carotid angiogram, anteroposterior view. Note minimal shift of anterior cerebral and marked uplift of middle cerebral arteries with a 'bare area' between the temporal bone and middle cerebral branches.

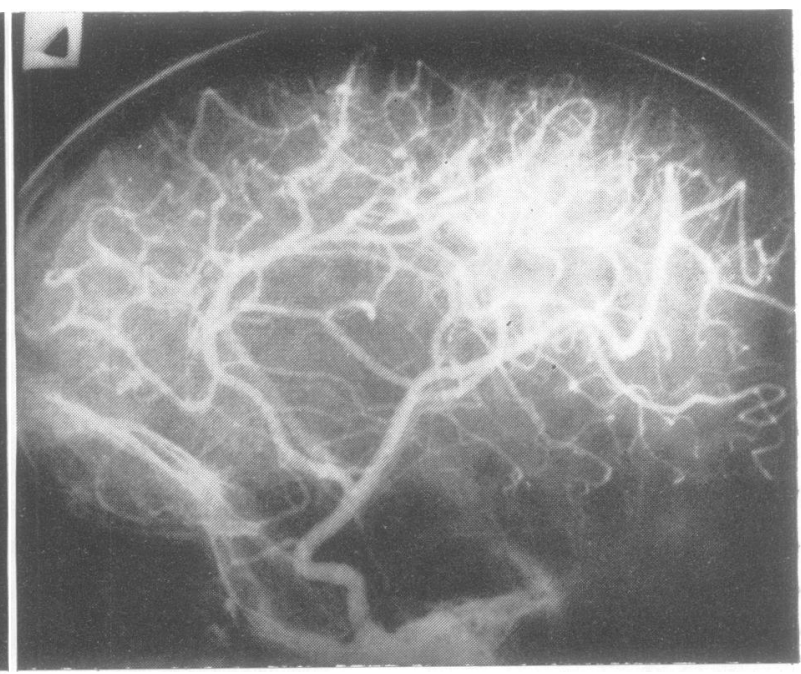

FIG. 4. Case 3. Left carotid angiogram, lateral view showing elevation of middle cerebral artery. 


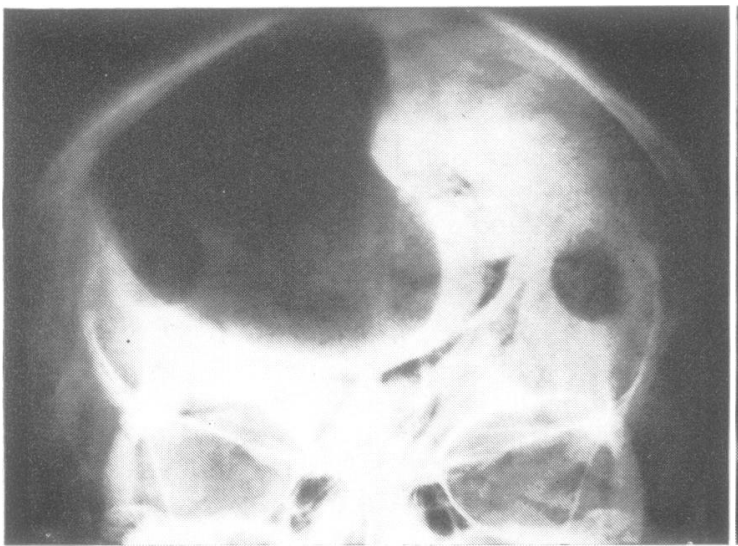

FIG. 5. Case 4. Ventriculogram. Note filling of the cyst only in anteroposterior view when the air was injected on the right side.

A $5 \mathrm{~cm}$ trephine disc in the right frontoparietal region was removed, and on opening the dura mater, a clear thin-walled cyst was seen. Eighty millilitres of clear colourless fluid were aspirated and the roof of the cyst was removed. Surrounding gyri were compressed. There was no communication between the cyst and the ventricles. The right ventricle was cannulated and distended by saline till the cyst cavity was obliterated. The dura mater was closed and the trephine disc replaced.

The postoperative course was satisfactory, and at the time of discharge, the stiffness of her hand was much improved. At the last follow up, seven years after operation, the patient is alive and well. The slight stiffness of the left upper limb still persists.



FIG. 7. Case 4. Further injection of air on the left side. Note the shifted ventricular system.

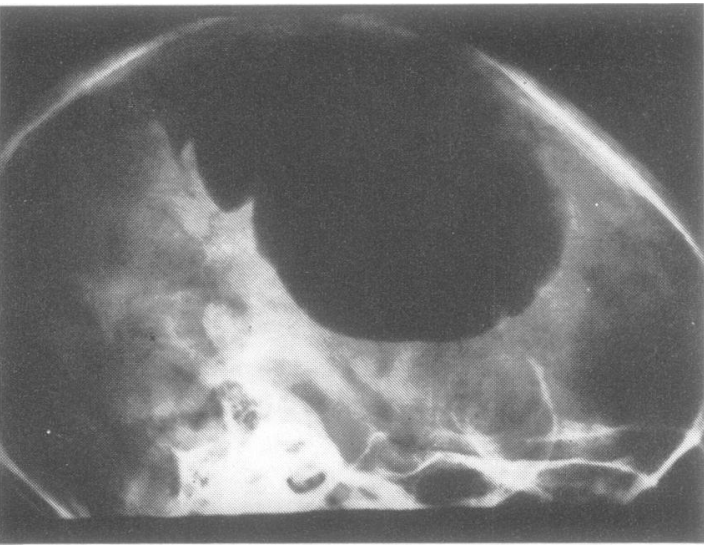

FIG. 6. Case 4. Note the filling of the cyst in lateral view.

\section{CASE 5}

(S.R.H. 7649.) G.H., a female aged 52 years, suffered right focal motor seizures for $1 \frac{1}{2}$ years. of There was no history of trauma or illness.

No abnormality was found on examination. Ap के EEG was normal and cerebrospinal fluid containe $40 \mathrm{mg}$ protein $/ 100 \mathrm{ml}$. A left carotid angiogran demonstrated a suspicious avascular area in the parietal region, without midline shift. She was place $\mathbb{D}$ on anticonvulsant medication.

Nine months later the patient was readmitted be cause of increasing seizure incidence, confusiofis speech difficulty, and slight weakness of right arint $\overrightarrow{0}$ and leg. A repeat carotid angiogram revealed a large $N$ avascular parasagittal space occupying lesion in the left parietal area.

A left parietal flap was turned down, and on opening the tense dura mater, a large cyst was seen in the parasagittal area, measuring $7 \mathrm{~cm}$ in diameter. The cyst had produced a distinct depression in the cortex, and its medial wall abutted on to the falx. Clear colourless fluid $(100 \mathrm{ml}$.) containing $34 \mathrm{mg}$ protein/ $100 \mathrm{ml}$. was aspirated and the roof of the cyst was removed. There was no communication between the cyst and the ventricles. The dura mater was closed and the bone flap replaced.

The speech defect cleared completely, but there was a slight residual right hemiparesis.

At follow-up examination, 12 months later, the patient was symptom free. Fifteen months later the original symptoms recurred, and an angiogram 을 showed clear evidence of the recurrence of the cyst. $\supset$ This was aspirated through a burr hole in the flap. 을 The patient improved, and at a follow up four months later she was well and leading a normal life. 


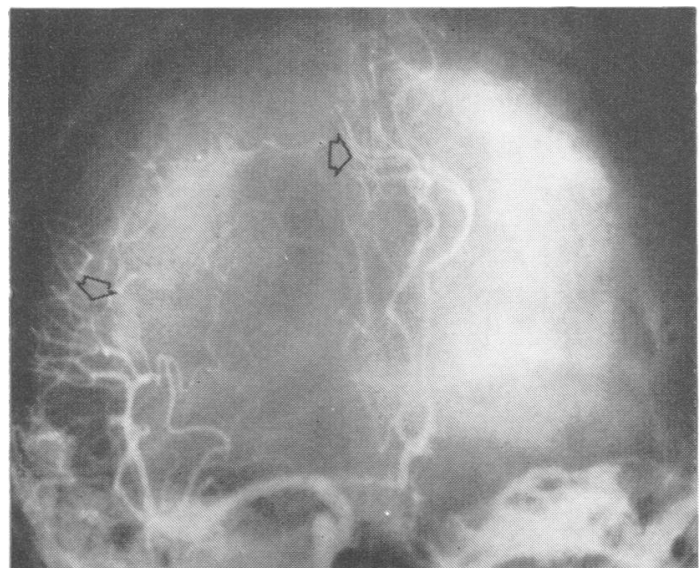

FIG. 8. Case 6. Right carotid angiogram, anteroposterior view. Note the shift of anterior cerebral artery to the left and depression of Sylvian point.

\section{CASE 6}

(S.R.H. 9107.) M.Y., a female aged 49 years, gave a history of gradually increasing stiffness of the left arm and leg for two years. There was no history of trauma or illness.

In July 1966, there was a marked cogwheel rigidity in the left upper and lower limbs, and a slight tremor in the left hand. Her gait was spastic and she did not swing the left arm. She was placed on anti-Parkinsonism medication for $2 \frac{1}{2}$ years, and was then referred to the neurosurgical clinic in August, 1969, as a possible case for thalamotomy.

On admission to the neurosurgical unit, examination showed slight left facial weakness, marked cog- wheel rigidity of the left limbs, and slight tremors of the left hand at rest. Power was minimally diminished on the left side, the jaw jerk was present, and the plantar reflexes were flexor. Sensibility to fine touch and pin prick was diminished and astereognosis was present on the left side.

A right carotid angiogram revealed a large avascular space occupying lesion in the parietal parasagittal area (Figs 8, 9, 10). The angiographic appearances were so reminiscent of case 5 , that a possibility of arachnoid cyst was strongly entertained.

A right parietal flap was turned down, and on opening the tense dura mater, a large cyst was seen in the parasagittal region, measuring $5 \mathrm{~cm}$ in diameter. The medial wall of the cyst abutted on to the falx, and laterally a distinct depression was seen in the cortex. Seventy millilitres of clear fluid containing $40 \mathrm{mg}$ protein $/ 100 \mathrm{ml}$. was aspirated and the roof of the cyst was removed. There was no communication between the cyst and the ventricles. The dura mater was closed and the flap replaced.

The postoperative course was uneventful, and at the time of discharge, all the features of Parkinsonism had cleared. At the last follow up (two years) she was normal and leading a full life.

HISTOLOGY The cyst wall consisted of a double layered fine membrane, each of flattened ependymal cells with oval darkly staining nuclei. Between the layers there was a collection of featureless fibres which were often collagenized without nuclei and occasional collection of ependymal cells.

\section{DISCUSSION}

Several types of brain cysts have been described


FIGS 9 and 10. Case 6. Right carotid angiogram, lateral view, early and late arterial phase. Note the avascular lesion in the parasagittal area. 
in the literature and they appear to fall into three main categories.

GROUP I: CONGENITAL PORENCEPHALIC CYSTS In this group the cyst cavity is created by a primary defect in the brain. Sometimes a thin membrane lies between the cyst cavity and the ventricles and the term pseudoporencephaly, incomplete porencephaly, or closed porencephaly are used (Pendergrass and Perryman, 1946). The primary cerebral defect is responsible for the symptoms and signs in such cases, the cyst being a passive and secondary development.

GROUP 2: SECONDARY CYSTS In this group the cyst develops secondary to a known aetiological factor such as trauma (Taveras and Ransohoff, 1953), infection, inflammation in leptomeninges, infarction, or haemorrhages. Neoplastic and parasitic cysts can also be grouped in this category. The symptoms and signs in these cases are due to the basic pathology in the brain and in part to the presence of the cyst.

GROUP 3: NON-COMMUNICATING CYSTS In this group the cysts lie in the brain substance and do not communicate with the ventricular system or the subarachnoid space. The cerebral cortex is merely compressed and indented and it is the cyst that gives rise to the symptoms and signs of raised pressure. They are usually found in the Sylvian region (Weinman, 1965), parasagittal region, or the cerebral convexity (Anderson and Landing, 1966). Similar lesions have been described in the posterior fossa (Trowbridge and French, 1952; Handa and Bucy, 1956; Oliver, 1958; Lewis, 1962), but in this communication only supratentorial cysts are considered. In the present series the cyst was in the Sylvian area in three cases, in the parasagittal region in two cases, and on the convexity in one (Table).

Various hypotheses have been put forward to explain the mechanism of cyst formation. Most authors believe that the cysts are congenital in origin. Recently Jakubiak, Dunsmore, and Beckett (1968) have reported four cases and discussed the mechanism of cyst formation. They believe that their two cases were due to developmental defect in the formation of the mantle layer and displacement of the ependymal cells into the subarachnoid space. These immature cells give origin to the cyst. The other two cases were thought to be representative of the cysts described by Starkman et al (1958) in which they demonstrated splitting of the arachnoid mater In our cases, histology of the cyst wall was ob tained in only three of the six cases, and case appears similar in origin to the first two cases of Jakubiak et al. (1968). It is difficult to speculate on the mechanism of cyst formation in the re

TA BLE

SUMMARY OF SIX CASES

\begin{tabular}{|c|c|c|c|c|c|c|}
\hline Case no. & 1 & 2 & 3 & 4 & 5 & 6 \\
\hline Age (yr) & 37 & $\begin{array}{l}46 \\
62\end{array}$ & $8 / 12$ & 57 & 52 & 49 \\
\hline $\begin{array}{l}\text { Sex } \\
\text { Year of treatment }\end{array}$ & $\begin{array}{l}M \\
1957\end{array}$ & $\begin{array}{l}\text { F } \\
1937 \\
1952\end{array}$ & $\begin{array}{l}M \\
1971\end{array}$ & $\begin{array}{l}F \\
1964\end{array}$ & $\begin{array}{l}F \\
1966 \\
1967\end{array}$ & $\begin{array}{l}F \\
1969\end{array}$ \\
\hline Clinical presentation & Ep. & $\begin{array}{l}\text { Ep. and } \\
\text { raised } \\
\text { ICP* }\end{array}$ & $\begin{array}{l}\text { Large head, } \\
\text { headache, } \\
\text { bilateral } \\
\text { 6th nerve } \\
\text { palsy }\end{array}$ & $\begin{array}{l}\text { Ep. } \\
\text { Raised } \\
\text { ICP. } \\
\text { L. hemi- } \\
\text { paresis }\end{array}$ & $\begin{array}{l}\text { Ep., } \\
\text { speech } \\
\text { defect, } \\
\text { (R) hemi- } \\
\text { paresis }\end{array}$ & $\begin{array}{l}\text { Parkinsonism, } \\
\text { cogwheel } \\
\text { rigidity } \\
\text { and } \\
\text { tremors (L) }\end{array}$ \\
\hline Lesion site & $\underset{L}{\text { Sylvian }}$ & $\underset{\mathbf{R}}{\text { Sylvian }}$ & $\underset{L}{\text { Sylvian }}$ & $\begin{array}{l}\text { Parietal } \\
\text { convexity } \\
\mathbf{R}\end{array}$ & $\underset{L}{\text { Parasagittal }}$ & $\underset{\mathbf{R}}{\text { Parasagittal }}$ \\
\hline Ventriculogram & + & + & + & (Diagnosis) & - & - \\
\hline Angiogram & + & - & + & - & + & 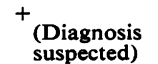 \\
\hline Treatment & Craniotomy & $\underset{\text { PM }}{\text { Craniotomy. }}$ & Craniotomy & Trephine & $\begin{array}{l}\text { Craniotomy. } \\
\text { Burr hole } \\
\text { aspiration }\end{array}$ & Craniotomy \\
\hline
\end{tabular}

* ICP = Intracranial pressure 
maining cases, but it seems likely that they are congenital in origin, since there is no obvious acquired cause.

Accepting that the cysts are congenital in origin, then the presentation of case 3 at the age of 8 months is understandable, but it is difficult to explain why the other five cases remained asymptomatic for so long, and presented only at ages between 37 to 57 years. Some arachnoid cysts remain silent and are encountered only incidentally at necropsy. Davison and Friedman (1946) described a case of a 70 year old man in which an apparently asymptomatic cyst in the right inferior frontal lobe was discovered at necropsy. They considered this to be a developmental defect. Similarly case 3 of Starkman et al. (1958) was asymptomatic during life and at no time was there any suspicion of an intracranial lesion. Their case 2 showed only partial ptosis as a symptom of the cyst found incidentally at necropsy. It is clear from these cases that a patient with a large cyst can remain symptom free during life.

Perhaps the development of the cyst is an extremely slow process and the brain is able to adjust to their presence. They do not produce reactive oedema in the surrounding brain and hence a state of compensation is maintained. Factors, such as minor trauma, which the patient may not recall, can initiate the process of decompensation, and thereby produce the signs and symptoms. Oliver (1958) described a case of arachnoid cyst presenting after a severe blow to the chest. Case 2 in the present series remained well for 15 years after the operation, and then a fall precipitated the fits and she later died of pulmonary oedema. The necropsy showed a large cyst which must have reformed during the 15 years but was not producing symptoms until the state of compensation was disturbed by trauma.

The clinical presentation varied in these six cases. Three presented with epilepsy and hemiparesis and one with epilepsy without signs. Case 6 was unusual and presented as Parkinsonism. It is accepted that certain intracranial tumours can present as Parkinsonism (Hunt and Lisa, 1927; Nicholson and Turner, 1964), subdural haematoma (Samiy, 1963), acute brain-stem compression (Oliver, 1959), and posterior fossa tumour (Reyes and De Vera, 1970). Only one case of arachnoid cyst has been reported to have pro- duced this syndrome and the cyst was in the posterior fossa (Musella and Elvidge, 1964). In case 6 the cyst was parasagittal and the mechanism of production of the Parkinsonian syndrome was presumably by chronic indirect compression of basal nuclei, in the same way that parasagittal tumours may produce this syndrome.

Case 3 presented as hydrocephalus. The arachnoid cyst was encountered in the course of craniotomy for suspected tumour or haematoma. A cyst in or near the Sylvian fissure is a rare cause of raised pressure in infants, Anderson et al. (1966) reported nine cases of supratentorial arachnoid cysts of which eight were infants presenting as hydrocephalus. The cyst in three of these cases was in the Sylvian fissure. Oliver (1958) and Lewis (1962) described single cases of arachnoid cysts presenting as hydrocephalus but the cysts were in the posterior fossa. Only a few more such cases are recorded in the literature.

Preoperative diagnosis of supratentorial cysts is seldom possible. They are mostly diagnosed at operation, sometimes on accidental entry of the cyst during ventriculography, but are occasionally suspected at angiography. In case 6 , diagnosis was strongly suspected on angiographic appearances, because of the recent experience with case 5 . After reviewing the angiograms in four of our cases, we believe that when there is a large avascular lesion shown by stretching and displacement of the vessels in an apparently well patient with minimal neurological signs, the possibility of arachnoid cyst is worth consideration, particularly if the lesion is angiographically in the Sylvian territory.

The result of treatment in these cases is highly gratifying. It is generally believed that craniotomy with a radical removal of non-adherent arachnoid mater usually proves adequate. Some surgeons have made communication between the cyst and the ventricles, and others have opened the subarachnoid spaces. In all our cases, the roof and non-adherent wall of the cysts were removed, the subarachnoid spaces were opened in three, and in one case the ventricle was distended by saline to obliterate the cyst cavity.

Four patients have remained well during the follow-up periods from four months to 14 years. In case 5 , a second evacuation of the cyst was required one year after the first operation, and the patient has been well for the past $3 \frac{1}{2}$ years. The 
second case remained well for 15 years after the initial operation, but then presented again with seizures and drowsiness after a fall. She died and, at necropsy, a large cyst was found with the signs of uncal herniation. It is possible that if the cyst had been evacuated she would have survived for many more years. Handa and Bucy (1956) reported three cases of arachnoid cyst and one of these cases showed signs of recurrence three times, requiring evacuation approximately every five years. This patient remained well for over 24 years. The liability of these cysts to recur and the necessity for re-evacuation has not been stressed by most authors, and a prolonged follow-up is not recorded. In view of our experience with recurrence in two of the six cases, we believe that a careful and prolonged follow-up should be conducted in all these cases. Prompt diagnosis and treatment is imperative, since the lesion is inherently benign and easily remediable.

I am grateful to Mr. B. H. Dawson and Mr. R. A. C. Jones for their permission to report the cases admitted to the Department of Neurosurgery. I am especially thankful to Mr. B. H. Dawson for his suggestions and criticism.

\section{REFERENCES}

Anderson, F. M., and Landing, B. H. (1966). Cerebral arachnoid cysts in infants. Journal of Pediatrics, 69, 88-96.

Davison, C., and Friedman, A. P. (1946). A cortical anomaly with some porencephalic features. Journal of Neuropathology and Experimental Neurology, 5, 225-232.
Handa, H., and Bucy, P. C. (1956). Benign cysts of the brain simulating brain tumors. Journal of Neurosurgery, 13, 489499.

Hunt, E. L., and Lisa, J. R. (1927). Frontal lobe tumor. A case simulating epidemic encephalitis, with Parkinson's syndrome. Journal of the American Medical Association, 89, 1674-1676.

Jakubiak, P., Dunsmore, R. H., and Beckett, R. S. (1968). Supratentorial brain cysts. Journal of Neurosurgery, 28, 129-136.

Lewis, A. J. (1962). Infantile hydrocephalus caused by arachnoid cyst. Case report. Journal of Neurosurgery, 19 431-434.

Musella, R., and Elvidge, A. R. (1964). Parkinsonian-like syndrome caused by cyst in posterior fossa. Report of a case. Journal of Neurosurgery, 21, 62-65.

Nicholson, A. N., and Turner, E. A. (1964). Parkinsonism produced by parasagittal meningiomas. Journal of Neurosurgery, 21, 104-113.

Oliver, L. C. (1958). Primary arachnoid cysts. Report of two cases. British Medical Journal, 1, 1147-1149.

Oliver, L. C. (1959). Parkinsonism due to midbrain compression. Lancet, 2, 817-819.

Pendergrass, E. P., and Perryman, C. R. (1946). Porencephaly. American Journal of Roentgenology, 56, 441-463.

Reyes, J. A. De V. (1970). Parkinsonian-like syndrome caused by posterior fossa tumor. Case report. Journal of Neurosurgery, 33, 599-601.

Samiy, E. (1963). Chronic subdural hematoma presenting a o Parkinsonian syndrome. Journal of Neurosurgery, 20, 903

Starkman, S. P., Brown, T. C., and Linell, E. A. $(1958 \mathrm{~b}$. Cerebral arachnoid cysts. Journal of Neuropathology an Experimental Neurology, 17, 484-500.

Taveras, J. M., and Ransohoff, J. (1953). Leptomeningea cysts of the brain following trauma with erosion of the skull. A study of seven cases treated by surgery. Journal Neurosurgery, 10, 233-241.

Trowbridge, W. V., and French, J. D. (1952). Benign arace noid cysts of the posterior fossa. Journal of Neurosurger 9, 398-404.

Weinman, D. F. (1965). Arachnoid cysts in the Sylvian fissure of the brain. Journal of Neurosurgery, 22, 185-187. 